\title{
RECONSTRUCCIÓN MANDIBULAR CON COLGAJO MICROVASCULARIZADO DE PERONÉ: REPORTE DE CASO
}

\author{
MICROVASCULAR RECONSTRUCTION WITH FIBULA FLAP: CASE REPORT
}

\author{
Stephanie, Cáceres-Quevedo ${ }^{1 a}$ Rómulo, Reaño-Salazar2b,1d Oscar, Broggi-Angulo2c,1d, Juan, Alegre-Carpio ${ }^{1 a}$, Raiza- \\ Bobadilla Oliva ${ }^{12}$ Karen, Loayza-Uturunco ${ }^{1 a}$
}

\begin{abstract}
RESUMEN
Paciente de sexo masculino de 10 años de edad, natural de la ciudad de Puno, que llega al servicio de cirugía de cabeza y cuello del Instituto Nacional de Salud del Niño por presentar una tumoración mandibular izquierda expansiva de 2 años de evolución de inicio insidioso y curso progresivo. Diagnóstico compatible con fibroma desmoplástico. Se realizó la resección del tumor mandibular, de hasta $10 \mathrm{~cm}$ de longitud, practicándose la hemimandibulectomía desde la región derecha hasta la zona preangular de la mandíbula. Durante ese acto quirúrgico se llevó a cabo el colgajo del peroné, en el mismo lado que la hemimandibulectomía. Una vez obtenido el peroné, se realizó la osteotomía para poder reconstruir el lecho receptor con las placas de reconstrucción unilock y se fijó con los tornillos. Finalmente se llevó a cabo la anastomosis. Uno de los más grandes retos del cirujano reconstructor es la cobertura de defectos complejos en extremidades, con exposición de tejidos profundos y en ocasiones con ausencia de los mismos. Como se describe en la literatura, el colgajo microvascularizado de peroné es la ideal y mejor opción para la reconstrucción de grandes defectos mandibulares, aun en casos pediátricos. Otros colgajos microvascularizados, como cresta iliaca, radio y escápula, ofrecen menor cantidad de hueso, mayor tasa de complicaciones en el sitio donador y los pacientes difícilmente pueden ser sometidos a rehabilitación dental posterior. Para este caso, el colgajo microvascularizado de peroné es la mejor opción para la reconstrucción mandibular. Después de la resección del tumor, el paciente no presentó afectación de la marcha.
\end{abstract}

Palabras clave: Colgajo, procedimientos quirúrgicos reconstructivos, microcirugía, peroné, mandíbula. (Fuente: DeCS BIREME)

\begin{abstract}
Patient male of 10-year-old native of the city of Puno, arriving at the service of head and neck surgery from the National Institute of health of the child to present an expansive left mandibular tumor of 2 years of evolution of insidious onset and progressive course. Compatible with Desmoplastic fibroma diagnosis. Resection of mandibular tumor, up to $10 \mathrm{~cm}$ in length, was practiced the hemimandibulectomy since the region right up to the preangular area of the jaw. During this surgical procedure the flap of the fibula, was conducted on the same side as the hemimandibulectomy. Once the fibula osteotomy was performed to rebuild the receptor bed with unilock reconstruction plates and was fixed with screws. Finally the anastomosis was carried out. One of the greatest challenges of the reconstructor surgeon is the coverage of complex defects in extremities, with exhibition of deep tissues and sometimes with absence of them. As described in the literature, the closure of fibula flap is the ideal and best choice for the reconstruction of major mandibular defects, even in pediatric cases. Other microvascularizados, such as iliac Crest, radio and scapula, flaps offer fewer bone, higher rate of complications at the donor site and patients can hardly be subjected to dental after-care. In this case, the closure of fibula flap is the best choice for mandibular reconstruction. After resection of the tumor, the patient did not affectation of the March.
\end{abstract}

Key words: Reconstructive Surgical procedures, microsurgery, fibula, flap, jaw. (Source:MESH NLM)

Recibido: 16 de agosto de 2017

1 Universidad de San Martin de Porres. Lima, Perú

${ }^{2}$ Instituto Nacional de Salud del Niño. Lima, Perú.

a Cirujano dentista

b Jefe del departamento de Medicina.

c Jefe del departamento de cabeza y cuello,

${ }^{\mathrm{d}}$ Docente de Internado Hospitalario

\section{Correspondencia:}

Stephanie Cáceres

Jr Johann Strauss 394 Dpto 202, San Borja. Teléfono: 987763055

Correo electrónico: stephanie.caceres@aol.com

Citar como: Cáceres-Quevedo S, Reaño-Salazar R, Broggi-Angulo Reconstrucción mandibular con colgajo microvascularizado de https://doi.org/10.24265/kiru.2017.v14n2.11
Aprobado: 20 de diciembre de 2017

Publicado: 30 de diciembre de 2017

Este es un artículo Open Access distribuido bajo la licencia Creative Commons Atribución-NoComercialCompartirlgual 4.

두(1)(2) 


\section{INTRODUCCIÓN}

El colgajo microvascularizado de peroné en la reconstrucción mandibular ha sido considerado un éxito en los últimos tiempos. Inicialmente fue descrito por Taylor en 1975(1). En 1979, Gilbert introdujo un abordaje lateral (2) y, posteriormente, Yoshimura, en 1983, agregó una isla cutánea para monitorizar la vascularidad del colgajo ${ }^{(3)}$.

La resección mandibular produce grandes defectos óseos y de partes blandas; se produce una retrusión del tercio inferior de la cara y una ptosis del labio inferior al involucrar zona sinfisiaria y parasinfisiaria. Cuando la resección afecta al cuerpo mandibular, produce asimetría con hundimiento facial del lado afectado; asimismo, incompetencia labial, trastornos en la fonación, masticación, deglución y, en ocasiones, incontinencia salival (en resección del arco anterior).

Además, al no reconstruir la mandíbula, esta tiende a la retrusión y desviación hacia el lado deresección. Se genera un cambio de movimientos de verticales a oblicuos que son controlados por una sola articulación, limitación en la motilidad y fuerza lingual (4).

Los injertos óseos como opción de reconstrucción solo están indicados en defectos óseos mandibulares menores a $4 \mathrm{~cm}$ ya que sirven de relleno y no sustituyen las características óseas. Se reabsorben y no producen osteoinducción.

Variedad de métodos y técnicas han sido reportadas en la literatura para conseguir la restauración de la continuidad mandibular deseada. Entre los que se destacan, en el año 2009, en el Instituto Nacional de Salud del Niño (INSN) de Lima, Perú, se publicó un reporte de caso en el que se presentaron tumoraciones que requirieron resecciones amplias, siendo necesaria la reconstrucción de defectos hasta de $15 \mathrm{~cm}$ de una hemimandíbula, en la cual se realizó una reconstrucción con colgajo libre de peroné más osteosíntesis con placa de reconstrucción y tornillos de titanio, previa fijación intermaxilar.

En el año 2012, en el Hospital Nacional Cayetano Heredia de Lima, Perú, se realizó una reconstrucción mandibular inmediata luego de la excéresis del tumor, realizándose la combinación de injertos autólogos de cortical externa de calota craneana y de cresta ilíaca particulada, consiguiéndose un volumen aceptablecon ambos para garantizar una adecuada regeneración ósea ${ }^{(5)}$.

Los objetivos de la reconstrucción mandibular son restablecer la simetría facial, la integridad anatómica funcional, fonación y de estética. Mediante un colgajo microvascularizado de peroné, al recibir nutrición propia se logra reducir al mínimo la reabsorción de las tablas óseas. De esta manera, el paciente podrá someterse posteriormente a la colocación de implantes dentales. Por otro lado, el presente estudio busca describir el reporte de caso y la particularidad de la utilización del colgajo libre microvascularizado de peroné.

\section{REPORTE DEL CASO}

Paciente de sexo masculino de 10 años de edad, natural de la ciudad de Puno, que llega al servicio de cirugía de cabeza y cuello del Instituto Nacional de Salud del Niño (INSN) por presentar una tumoración mandibular izquierda expansiva de 2 años de evolución de inicio insidioso y curso progresivo. El paciente refería dolor espontáneo e intermitente en la región mandibular izquierda. No constató limitación a la apertura oral ni parestesia del labio inferior.

La madre refiere que cinco años antes del ingreso al servicio su hijo presentó un aumento en la hemicara inferior izquierda, por lo cual fue referida al Hospital Hipólito Unanue, y se le realizó una biopsia y examen anátomo-patológico. Dos años después, nuevamente notó aumento en la hemimandíbula izquierda asociado a dolor espontáneo por lo que en esta ocasión fue referido al INSN.

La exploración física objetivó una tumoración de $10 \mathrm{~cm}$ a nivel del cuerpo mandibular izquierdo con desplazamiento de la cortical externa (Figura 1). La exploración intraoral mostró una lesión de consistencia firme y de límites difusos y con reabsorción de la cortical vestibular mandibular izquierda y expansión de la tabla ósea interna (Figura 2). 

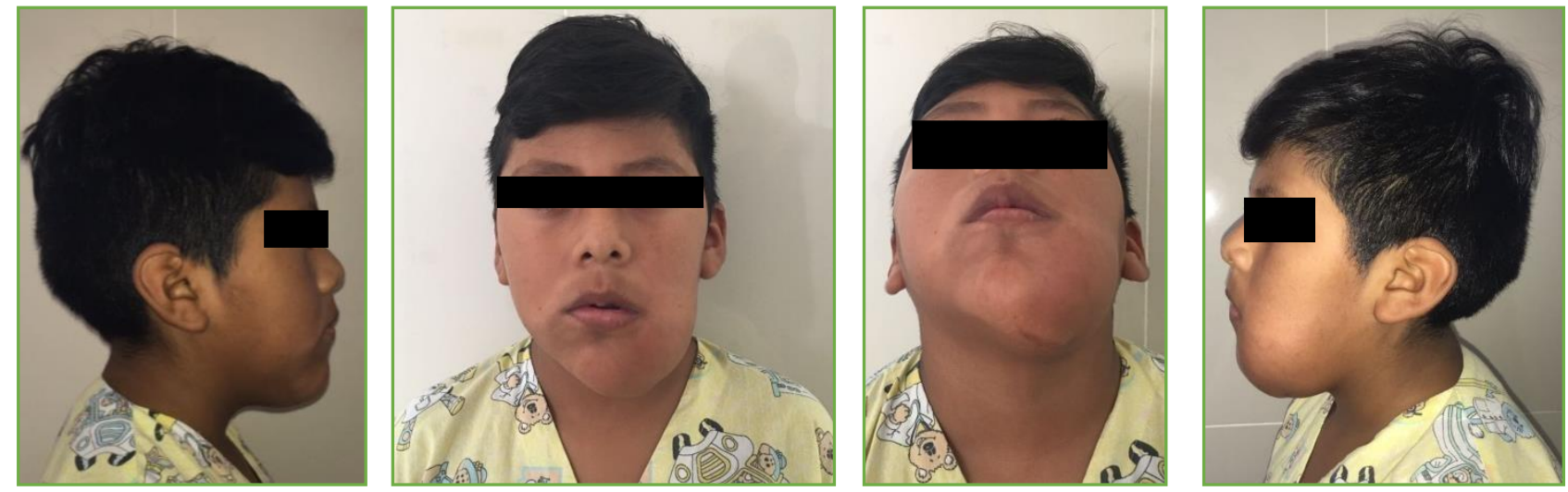

Figura.1 Registro fotográfico inicial. Se observa una tumoración de $10 \mathrm{~cm}$ a nivel del tercio facial inferior izquierdo.
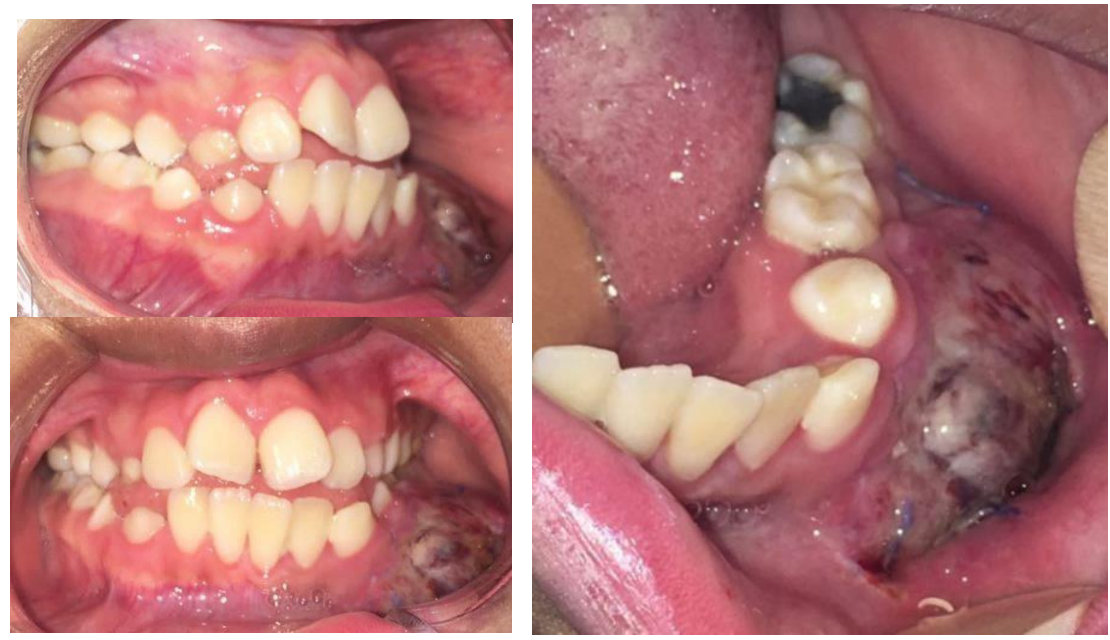

Figura.2 Exploración intraoral que muestra una lesión de consistencia firme y límites difusos

Así mismo, se constató protrusión de los tejidos blandos adyacentes. La radiografía panorámica mostró una imagen radiolúcida multilocular, con patrón osteolítico de bordes parcialmente definidos, a nivel del cuerpo mandibular izquierdo (Figura 3). La tomografía computarizada en sentido céfalo caudal evidenció una lesión isodensa, multilocular con presencia de tabiques intralesionales. Se encuentra a nivel del tercer cuadrante de raíces hasta base expandiéndola, deformándola y reabsorbiéndola (Figura 4).
En el corte axial se observa expansión de la tabla lingual, reabsorción de la tabla vestibular, desplazamiento de tejidos blandos adyacentes, sin infiltrado. En el corte coronal vemos una ventana de tejidos blandos, evidenciando una lesión tumoral y no quiste, que se expande hacia caudal. Finalmente, en el corte sagital, se evidencia pérdida de continuidad del nervio dentario inferior, se observa desplazamiento de raíces sin ser reabsorbidas (Figura 5). También se solicita una reconstrucción tridimensional (Figura 6) 


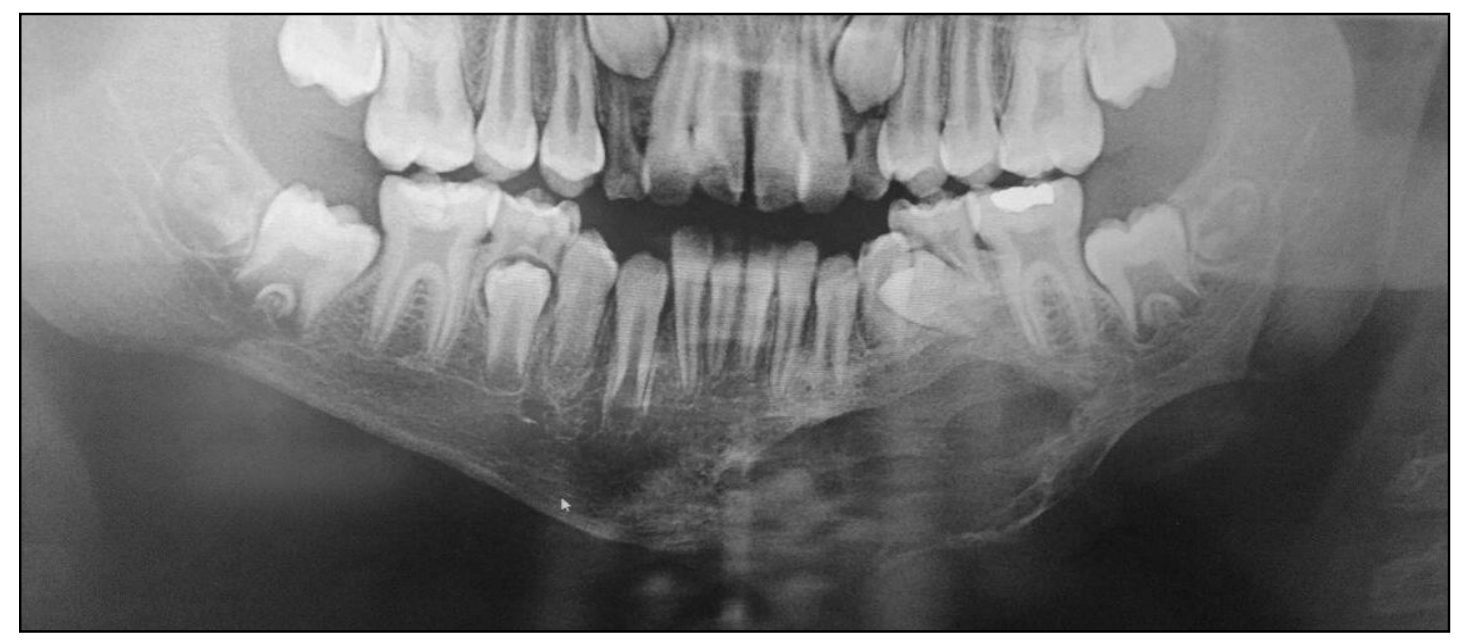

Figura.3 Radiografía panorámica con imagen radiolúcida multilocular, con patrón osteolítico, bordes parcialmente corticalizados a nivel del cuerpo mandibular izquierdo.
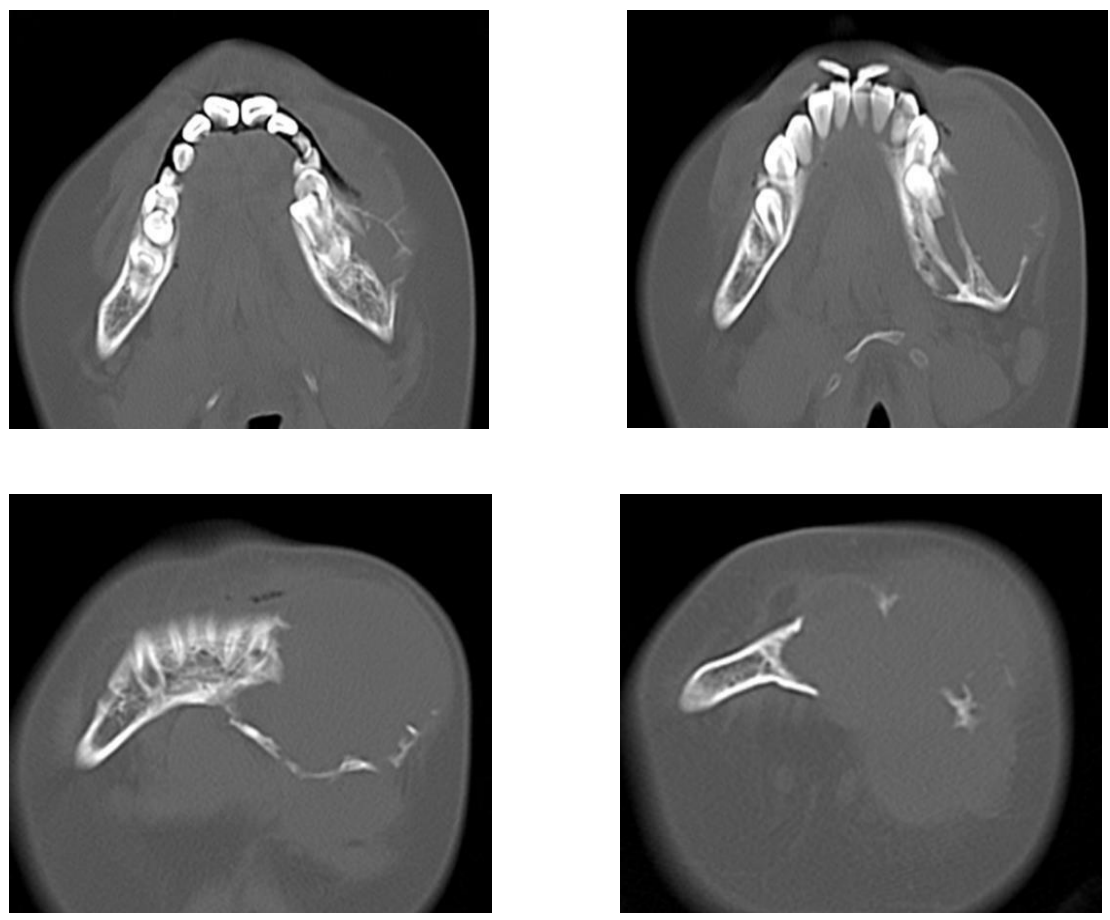

Figura 4. Corte axial: Expansión de tabla vestibular, reabsorción tabla lingual. Se insinúa, se manifiesta y se evidencia. 

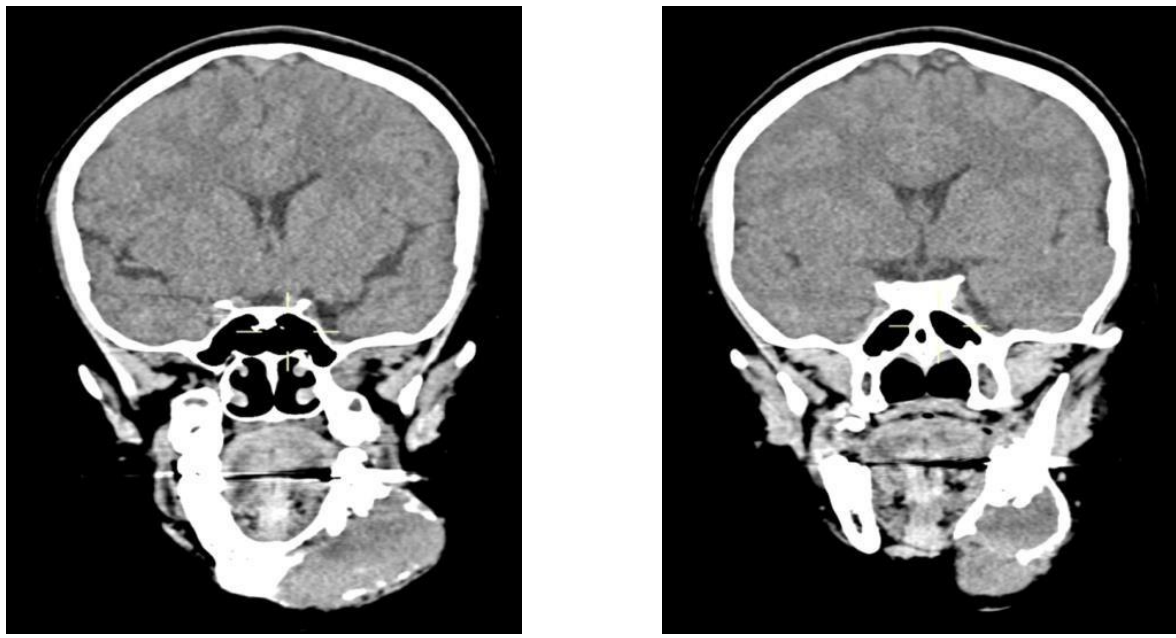

Figura 5. Corte coronal: ventana de tejidos blandos, lesión tumoral con expansión hacia caudal. La lesión se extiende de la línea media contralateral.

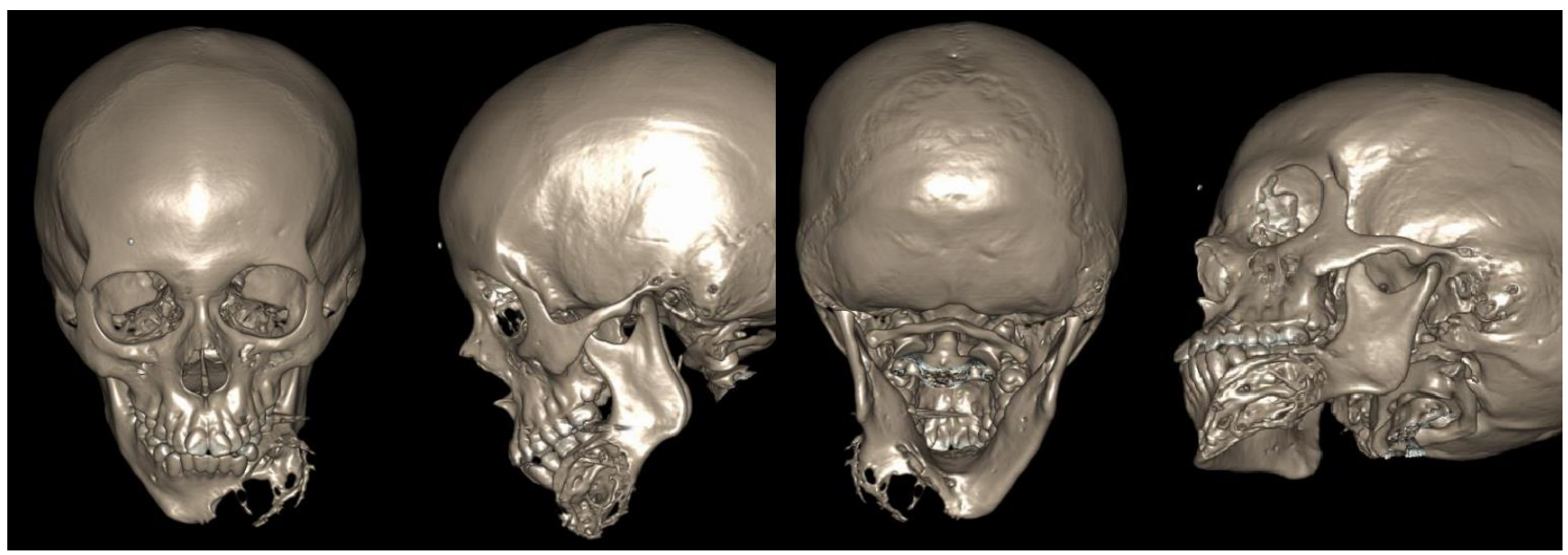

\section{Figura 6. Reconstruccionen 3D}

En la primera parte del plan de tratamiento se decidió realizar una biopsia incisional con examen anatomopatológico, y la segunda fase de tratamiento se realizó de acuerdo con los resultados. La biopsia diagnóstica demostró la presencia de hallazgos histológicos compatibles con neurofibroma (Figura 7). Para obtener un resultado más preciso de la biopsia, esta se mandó al INEM, cuyo resultado fue un fibroma desmoplásico.

Con el diagnóstico de la biopsia se decidió armar el plan de tratamiento de la segunda fase, que consistió en la resección del tumor mandibular y reconstrucción con colgajo libre microvascularizado de peroné.

Se realizó la resección del tumor mandibular de hasta $10 \mathrm{~cm}$ de longitud mediante un abordaje combinado intra y extraoral (incisión tallo verde), practicándose la hemimandibulectomía desde la región derecha hasta la zona preangular de la mandíbula (Figura 8 y 9). Durante ese acto quirúrgico se llevó a cabo el colgajo del peroné, que fue del mismo lado que la hemimandibulectomía. (Figura 10) 

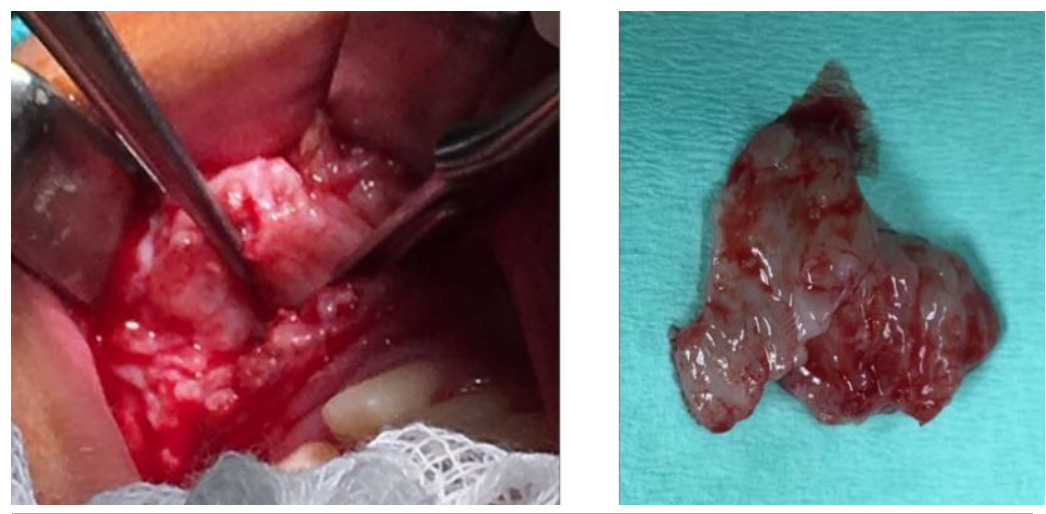

Figura 7. Toma de biopsia incisional para el diagnóstico presuntivo y resultado de la biopsia

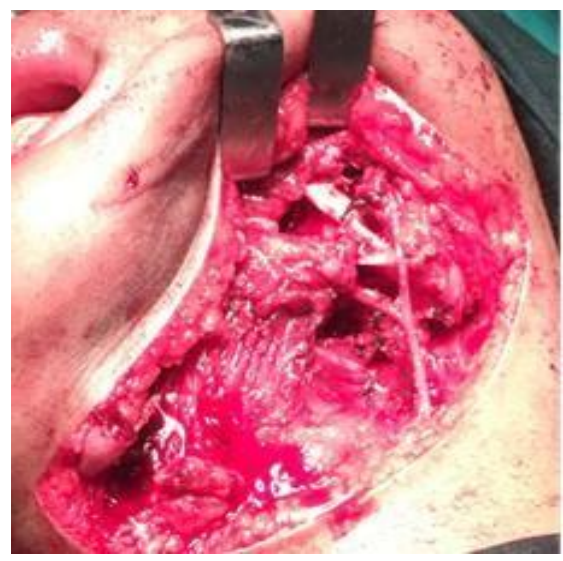

Figura 8. Se observa el abordaje extraoral y la

hemimandibulectomía que abarco un espacio de $10 \mathrm{~cm}$.

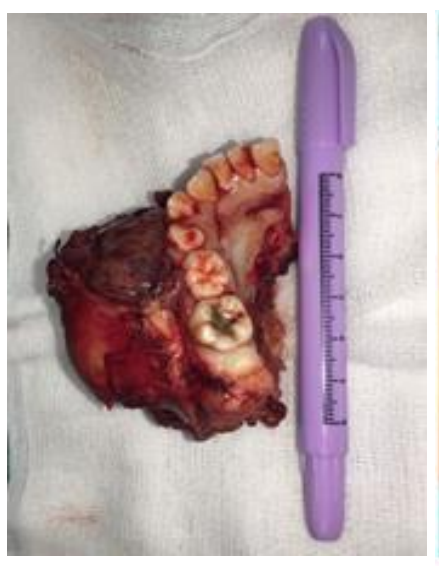

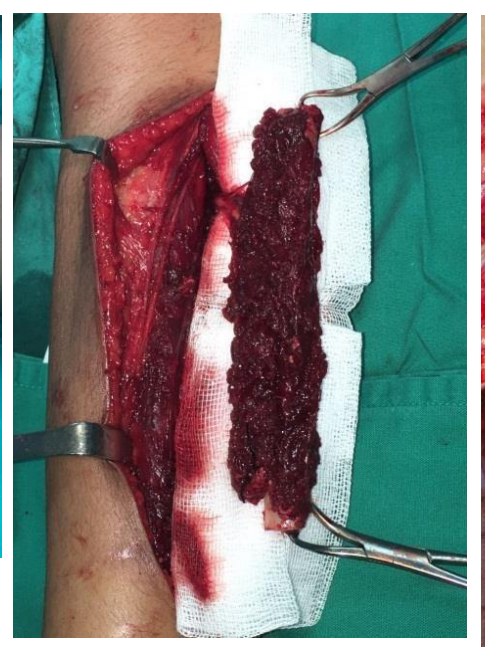

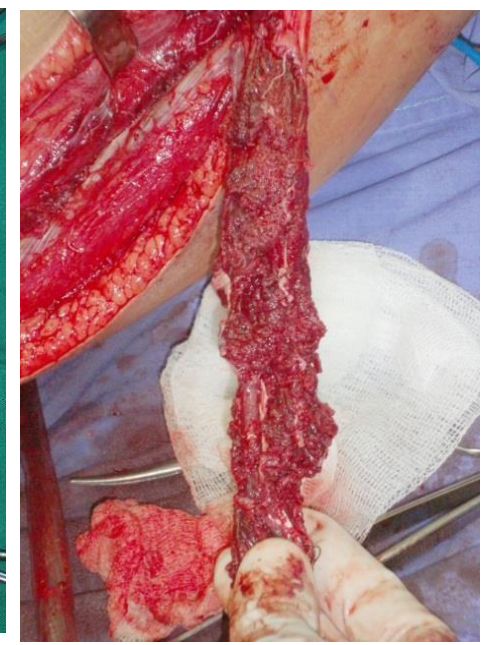

Figura 10. Levantamiento del colgajo de peroné 
Una vez obtenido el injerto del peroné se realizará la osteotomía, para poder reconstruir el lecho receptor con las placas de reconstrucción unilock y se fijarácon los tornillos unilock (Figura 11).

Luego se realizará la anastomosis microquirúrgica de la arteria y vena peronea con la arteria y vena facial, teniendo en cuenta que deberán tener una angulación de $45^{\circ}$. No debe ser perpendicular. Se sutura con hilo de $8 / 0$ nylon (Figura 12). Terminada la anastomosis microquirúrgica se debe producir el sangrado (Figura 13).

El acto quirúrgico termina con el cierre de la zona donante y de la zona receptora.

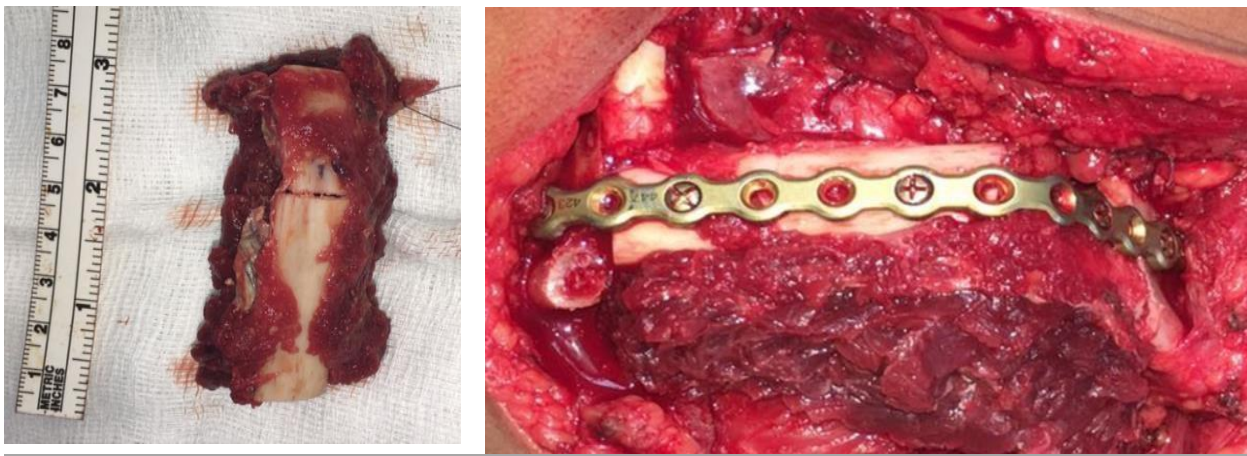

Figura 11. Osteotomía del colgajo y reconstrucción en el lecho receptor, fijado con placa y tornillos unilock.

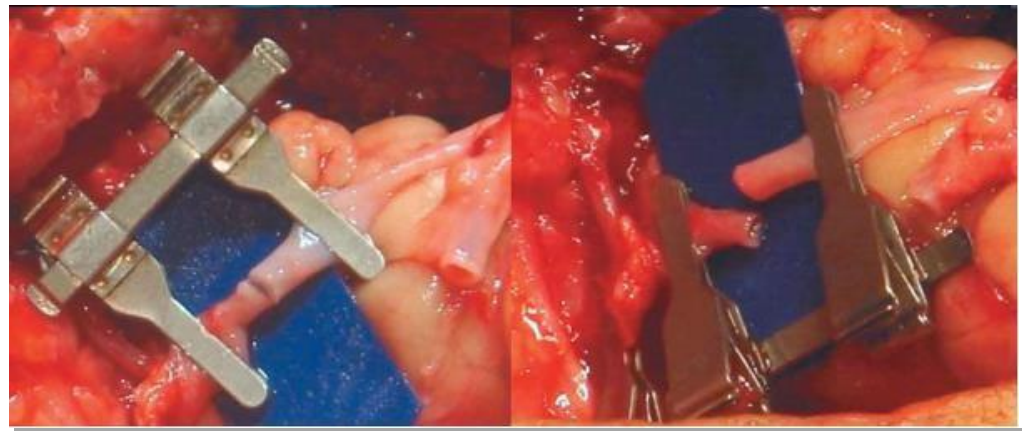

Figura 12. Anastomosis microquirúrgica de la arteria y vena peronea con la arteria y vena facial.
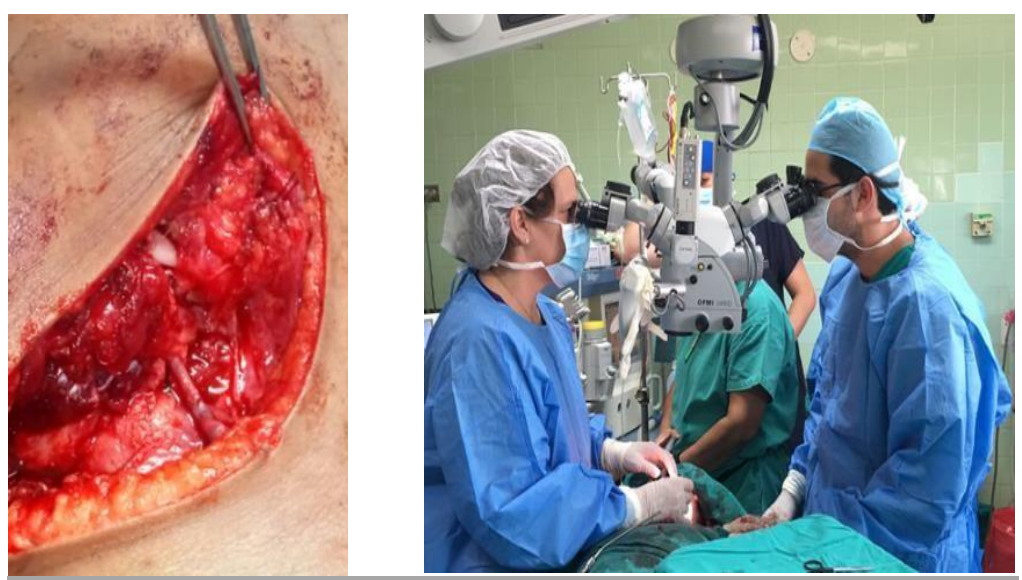

Figura 13. Sangrado de la anastomosis microquirúrgica y terminación del acto quirúrgico. 
A

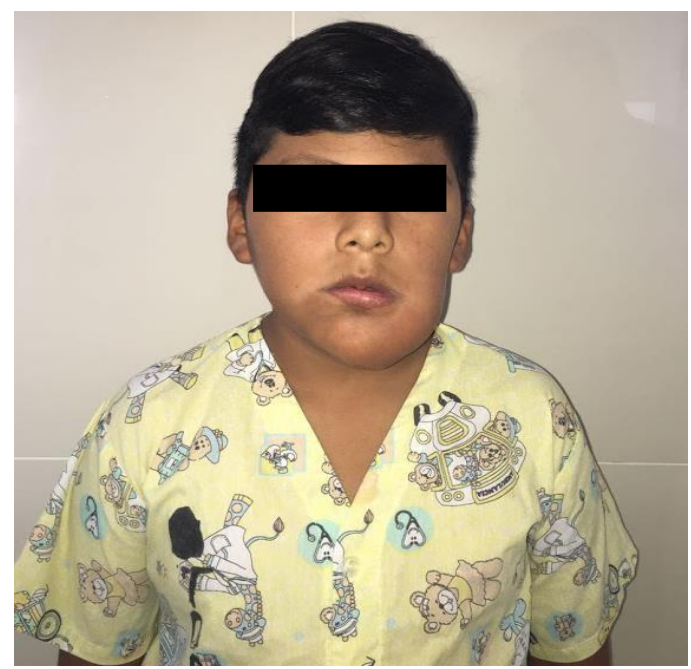

B

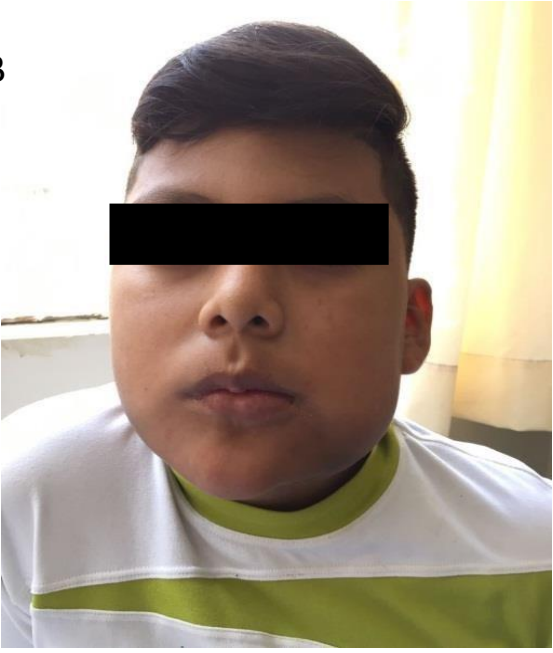

Figura 14 A. Registro fotográfico preoperatorio. B. Fotografía postoperatoria.
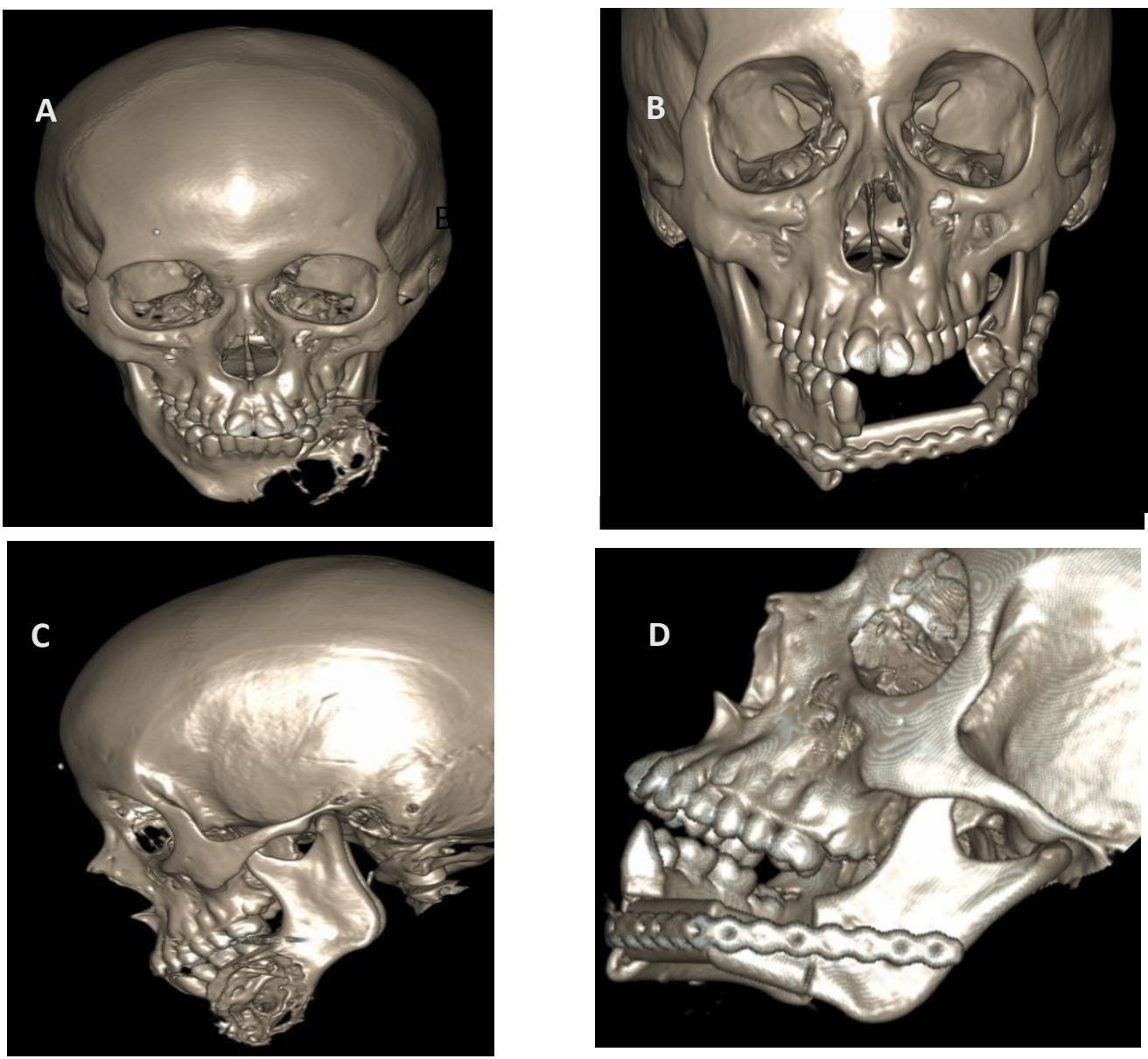

Figura 15. Imágenes en 3D. A Vista frontal preoperatoria B Vista frontal posoperatoria. C. Vista lateral preoperatoria. D. Vista lateral postoperatoria. 


\section{DISCUSIÓN}

Uno de los más grandes retos del cirujano reconstructor es la cobertura de defectos complejos en extremidades, con exposición de tejidos profundos y en ocasiones con ausencia de los mismos. Desde que Taylor et al. en el año 1975 describieron el colgajo libre de peroné, este ha sido la opción reconstructiva más utilizada, al brindarhasta $25 \mathrm{~cm}$ de largo para reconstruir defectos óseos grandes, siendo este un hueso bicortical (6).

Consideramos el colgajo de hueso vascularizado de peroné como el más idóneo para la reconstrucción de pérdidas mandibulares, coincidiendo con muchos autores en esta afirmación, por las ventajas que posee con relación al colgajo de cresta iliaca y hueso escapular.

Otros colgajos microvascularizados como la cresta iliaca, el radio y la escápula ofrecen menor cantidad de hueso, mayor tasa de complicaciones en el sitio donador, y los pacientes difícilmente pueden ser sometidos a rehabilitación dental posterior ${ }^{(5,6)}$.

El contorno mandibular es uno de los parámetros que nos permite evaluar los resultados estéticos logrados. El colgajo de peroné permite porsu vascularidad, seccionarlo en varios segmentos sin afectar su irrigación y adaptarlo al defecto a reparar. Coincidimos con otros autores que atribuyen sus buenos resultados reconstructivos a las bondades que facilita el peroné al conformar la nueva mandíbula. El colgajo de cresta iliaca y escapular no admite poderlo seccionar, aspecto que lo limita para las reconstrucciones mandibulares.

Como se describe en la literatura, el colgajo microvascularizado de peroné es la ideal y mejor opción para la reconstrucción de grandes defectos mandibulares, aun en casos pediátricos ${ }^{(6)}$.

Según los estudios, el área más frecuente donde podemos encontrar el fibroma desmoplásico es la mandíbula, el cual se presenta como una tumoración mandibular que produce tanto una alteración estética como sensitiva y funcional en los pacientes ${ }^{(7)}$.

En concordancia con el artículo publicado por el INSN, para la reconstrucción mandibular se requiere de un abordaje extraoral, el cual nos otorga una excelente exposición a los bordes de sección mandibulares para la realización de la osteosíntesis y la microanastomosis sin dificultades. Es imperativa la fijación intermaxilar, de modo que la vía aérea se asegure con un tubo nasotraqueal anillado en nuestro caso, sin requerir de traqueostomía alguna $(3,6)$.

Según un estudio realizado en Cuba ${ }^{(8)}$, la evolución de todos los pacientes fue satisfactoria (100\%) y alcanzó un porcentaje superior al reportado por otros autores, que osciló entre el 75 y el $98 \%$.

El tiempo quirúrgico promedio alcanzado puede ser considerado como muy bueno en este tipo de cirugía, y se logró porque la intervención fue efectuada por dos equipos quirúrgicos que trabajaron simultáneamente. La recuperación funcional y estética del paciente ha sido satisfactoria y coincide con lo reportado por otros autores (Figuras 14 y 15).

\section{CONCLUSIONES}

Dentro de las manifestaciones más frecuentes del fibroma desmoplásico, este se ubica al nivel de la mandíbula, como en el caso clínico presentado. La resección del tumor se realiza mediante un abordaje intra y extraoral.

Para este caso, el colgajo microvascularizado de peroné es la mejor opción para la reconstrucción mandibular después de la resección del tumor. El éxito de este caso clínico se debió a que la anastomosis microvascular se realizó de manera óptima, logrando la vascularización del colgajo. Finalmente, después del post-operatorio el paciente no presentó afectación de la marcha.

Contribuciones de autoría: RRS y OBA fueron responsables del diagnóstico y tratamiento del paciente. SCQ, JAC, RBO y KLU asistieron en estos procedimientos. Todos los autores aprobaron la versión final de este reporte de caso.

Conflictos de interés: Los autores manifestaron no tener ningún tipo de conflicto de interés en esta publicación.

\section{REFERENCIAS BIBLIOGRÁFICAS}

1. Taylor GI, Miller DH, Ham FJ. The free vascularized bone graft. A clinical extension of microvascular techniques. Plast Reconstr Surg 1975; 55: 533-44.

2 Gilbert A. Vascularized transfer of the fibular shaft. Intern J Microsurg. 1979: 100-102

3. Yoshimura M, Shimamura K. Free vascularized fibular transplant. A new method for monitoring circulation of the 
grafted fibula. J Bone Joint Surg Am. 1983; (65): 12951305.

4. Oré-Acevedo JF, Broggi-Angulo OA, La Torre-Caballero M, Wiegering-Cecchi A, De Pawlikowski-Amiel W, LazoNuñez M. Reconstrucción mandibular con colgajo microquigúrgico de peroné en el Instituto Especializado de Salud del Niño, Lima, Perú. Acta Méd. Per. 2009; 26(2).

5. Ventura-Ponce $H$, Cabrera E, Delgado-Azañero W, Huamani-Parra J, Ccahuana-Vásquez V, Lozano-Aquije W, Gárate A. Reconstrucción mandibular con combinación de injertos autólogos libres e instalación de implantes dentales: Reporte de Caso. Rev Estomatol Herediana. 2012; 22(4): 216-22.
6. Gallegos-Hernández J, Martínez-Miramón A. Trasplante de peroné para reconstrucción mandibular en pacientes sometidos a mandibulectomía por tumores óseos y de la cavidad bucal. Experiencia de 10 años. Gac Méd Méx. 2008; 144 (2).

7. González-García R, Rodríguez-Campo $F$, et al. Reconstructive considerations by means of the vascularized fibular free flap. Med Oral Patol Oral Cir Bucal 2006; 11: E531-5.

8. Cruz-Rivero T, Ferbeyre-Binelfa L, Azcue-Bilbao M. Reconstrucción mandibular con el colgajo libre del peroné. Rev Cubana Med. 2003; (42) 4 